\title{
Lipopolysaccharide promotes adhesion and migration of murine dental papilla-derived MDPC-23 cells via TLR4
}

\author{
JONG-HWAN PARK ${ }^{1}$, SEONG-MIN KWON ${ }^{2}$, HYO-EUN YOON ${ }^{2}$, SOO-A KIM ${ }^{3}$, \\ SANG-GUN AHN ${ }^{2}$ and JUNG-HOON YOON ${ }^{2}$
}

\author{
${ }^{1}$ Department of Biochemistry, College of Medicine, Konyang University, Daejeon 302-711; ${ }^{2}$ Department of Pathology, \\ School of Dentistry, Chosun University, Gwangju 501-759; ${ }^{3}$ Department of Biochemistry, \\ Dongguk University College of Oriental Medicine, Gyeongju 780-714, Republic of Korea
}

Received August 26, 2010; Accepted October 29, 2010

DOI: $10.3892 / \mathrm{ijmm} .2010 .568$

\begin{abstract}
Odontoblasts and/or dental pulp cells are responsible for tooth repair and dentin formation. Furthermore, adhesion and migration are critical processes for tissue regeneration. This study was performed to clarify whether lipopolysaccharide (LPS) modulates adhesion and migration of the murine odontoblast-like cell line MDPC-23, and whether Toll-like receptor 4 (TLR4) signaling is engaged in this process. TLR4 expression in MDPC- 23 cells was examined by RT-PCR. Adhesion assay was performed using type I collagen-coated plates. Migration ability was determined by a commercial assay kit. Phosphorylation of IкB- $\alpha$, FAK, $\mathrm{AKT}$, and ERK was examined by Western blot analysis. TLR4 was functionally expressed in MDPC-23 cells. LPS treatment enhanced adhesion and migration of MDPC-23 cells in a dose-dependent manner. Blockade of TLR4 using its antibody restored LPS-induced adhesion and migration of MDPC-23 cells. These findings indicate that LPS, an immune activator from Gram-negative bacteria, can promote the adhesion and migration ability of MDPC-23 cells via TLR4.
\end{abstract}

\section{Introduction}

Innate immune response is the first line of defense against infection, which is mainly mediated by macrophages and dendritic cells. Pattern recognition receptors (PRRs) initiate the innate immune response through recognition of pathogen associated molecular patterns (PAMPs), such as lipopolysaccharide (LPS). Among PRRs, Toll-like receptors (TLRs) are the best characterized receptors. TLRs sense microbial molecules including LPS, lipoproteins, lipoteichoid acid

Correspondence to: Dr Sang-Gun Ahn or Dr Jung-Hoon Yoon, Department of Pathology, School of Dentistry, Chosun University, 375 Seoseok-dong, Dong-gu, Gwangju 501-759, Republic of Korea E-mail: ahnsg@chosun.ac.kr

E-mail: jhyoon@chosun.ac.kr

Key words: adhesion, lipopolysaccharide, migration, odontoblast, Toll-like receptor
(LTA), dsRNA, ssRNA, and CpG motif from bacterial DNA $(1,2)$. Following recognition, TLRs activate NF- $\mathrm{KB}$ and mitogen-activated protein kinases (MAPKs) through the MyD88- or the TRIF-dependent pathway and consequently lead to production of proinflammatory cytokines $(1,2)$.

Odontoblasts and/or dental pulp cells are neural crestderived mesenchymal cells, which regulate the pulp immune responses triggered by oral bacteria $(3,4)$. A recent study showed that TLR2 and TLR4 are functionally expressed in human odontoblasts and LPS stimulation leads to upregulation of proinflammatory mediators such as IL-1B, TNF- $\alpha$, and human $\beta$ defensin-2 (hBD-2). In addition, Durand et al revealed that mRNAs of TLR1-6 and TLR9 were expressed in human odontoblasts and LTA stimulation led to an increase in gene and protein expression of TLR2 and to an induction of NF- $\mathrm{kB}$ activation (3). These findings suggest that odontoblasts may play an important role for the immune response against oral bacteria through TLR signaling.

In addition to the immune responses, odontoblasts and/or dental pulp cells are also involved in tooth repair and regeneration as well as in dentin formation (dentinogenesis), although the precise mechanism remains to be fully elucidated. Following enamel disruption, odontoblasts and/or dental pulp cells are exposed to bacteria entering dentin from the oral cavity, which may trigger tissue repair processes as well as inflammatory responses of odontoblasts and/or dental pulp cells. It has been known that TLR signaling is involved in tissue repair and regeneration as well as in the immune response (5-7). However, little is known about the role of TLR signaling on the tissue repair process of odontoblasts and/or dental pulp cells. Cell adhesion and migration are the critical processes for tissue repair in a variety of physiological and pathological conditions as well as in tumor metastasis. Therefore, in this study, we examined whether LPS, a Gramnegative bacterial molecule, affects adhesion and migration of a murine dental papilla-derived MDPC- 23 cells and whether TLR4 is required for these effects.

\section{Materials and methods}

Cell culture and reagents. MDPC-23 cells $(8,9)$, murine dental papilla-derived odontoblast-like cells, were cultured in 
Dulbecco's modified Eagle's medium (DMEM) supplemented with $10 \%$ fetal bovine serum, $100 \mu \mathrm{g} / \mathrm{ml}$ streptomycin, 100 units $/ \mathrm{ml}$ penicillin and $100 \mu \mathrm{g} / \mathrm{ml}$ non-essential amino acids at $37^{\circ} \mathrm{C}$ in a $5 \% \mathrm{CO}_{2}$ humidified incubator. Ultrapure LPS from E. coli 0111:B4 was purchased from Invitrogen (San Diego, CA, USA). The TLR4 antibody was from ImGenex (San Diego, CA, USA).

Reverse transcription-polymerase chain reaction ( $R T-P C R)$. Total RNA was extracted from MDPC-23 cells or mouse spleen tissue, using Qiagen RNeasy mini kit (Valencia, CA, USA). Total RNA ( $1 \mu \mathrm{g})$ was reverse transcribed into cDNA and PCR was performed using the Superscript ${ }^{\mathrm{TM}}$ one-step RT-PCR with Platinum ${ }^{\circledR}$ Taq kit (Invitrogen). The following primer sets were used. TLR4: F: 5'-GTGGTACCTGAG AATGATGTGGG-3' and R: 5'-GTTAAGGAAGTCAGGAA CTGGGTG-3'; GAPDH: F: 5'-CCAAGGTCATCCATGAC AACTTTG-3' and R: 5'-GTCATACCAGGAAATGAGCTT GACA-3'. PCR conditions were as follows: $94^{\circ} \mathrm{C}$ for $3 \mathrm{~min}$, 35 cycles for TLRs or 25-30 cycles for GAPDH consisting of $94^{\circ} \mathrm{C}$ for $30 \mathrm{sec}, 60^{\circ} \mathrm{C}$ for $30 \mathrm{sec}, 72^{\circ} \mathrm{C}$ for $30 \mathrm{sec}$, and $72^{\circ} \mathrm{C}$ for $10 \mathrm{~min}$. PCR products were then electrophoresed on a $1.5 \%$ acrylamide gel and visualized using a gel documentation system (Bio-Rad, Hercules, CA, USA).

Cell adhesion assay. Type I collagen (50 $\mu 1)$ diluted in PBS was added to each well of 96-well plates and placed at $4^{\circ} \mathrm{C}$ overnight. Subsequently, each well was rinsed with PBS and non-specific binding sites were blocked with $1 \% \mathrm{BSA}$ at $37^{\circ} \mathrm{C}$ for $1 \mathrm{~h}$. Various doses of LPS were added to each well for $30 \mathrm{~min}$ and subsequently $5 \times 10^{4}$ cells were placed in each well and allowed to adhere at $37^{\circ} \mathrm{C}$ for $30-90 \mathrm{~min}$. Nonadherent cells were rinsed off with PBS, and the remaining cells were fixed with $4 \%$ paraformaldehyde for $5 \mathrm{~min}$. The cells were stained with $0.5 \%$ toluidine blue in $4 \%$ paraformaldehyde for $5 \mathrm{~min}$ and finally rinsed in water. The cells were solubilized with the addition of $100 \mu 1$ of $1 \%$ SDS and the optical density was measured by a Microplate Autoreader ELISA (Bio-Tek Instruments Inc., Winooski, VT, USA) at $595 \mathrm{~nm}$.

Cell migration assay. The cell migration assay was performed using a Chemotaxis Cell Migration Assay kit (Chemicon) according to the manufacturer's instructions. The cells were collected by trypsinization and resuspended in serum-free medium at a density of $2.5 \times 10^{4} / \mathrm{ml}$. The cells were added onto the insert and treated with various doses of LPS in the media. The cells were then allowed to migrate for $24 \mathrm{~h}$ at $37^{\circ} \mathrm{C}$. The cells that migrated to the lower surface of the membrane were fixed with methanol and stained with hematoxylin for $5 \mathrm{~min}$. The number of migrated cells on the lower side of the membrane was counted from five randomly selected high power fields (x200).

Western blot analysis. The cells treated with LPS were lysed with $2 X$ SDS sample buffer. The proteins were resolved by SDS-PAGE and transferred onto PVDF membrane. After blocking with $5 \%$ skim milk in TBS at room temperature for $1 \mathrm{~h}$, the membranes were incubated with IкB- $\alpha$, phosphoIкB- $\alpha$, phospho-ERK (Cell Signaling, Danvers, MA, USA),

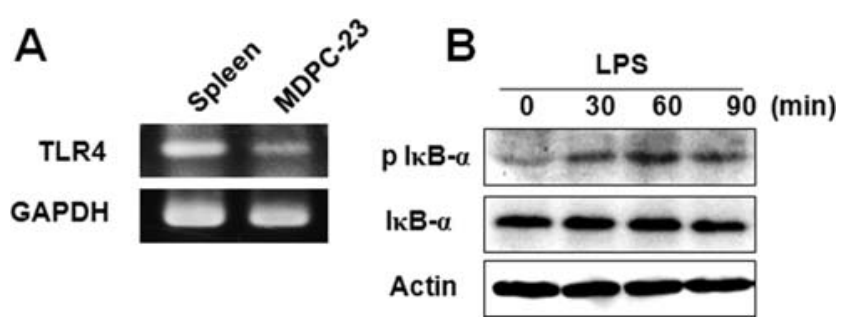

Figure 1. (A) Gene expression of TLR4 was examined by RT-PCR in mouse spleen and in MDPC-23 cells. (B) MDPC-23 cells were treated with LPS $(1 \mu \mathrm{g} / \mathrm{ml})$ and phosphorylation of I $\mathrm{B}-\alpha$ was examined by Western blot analysis.

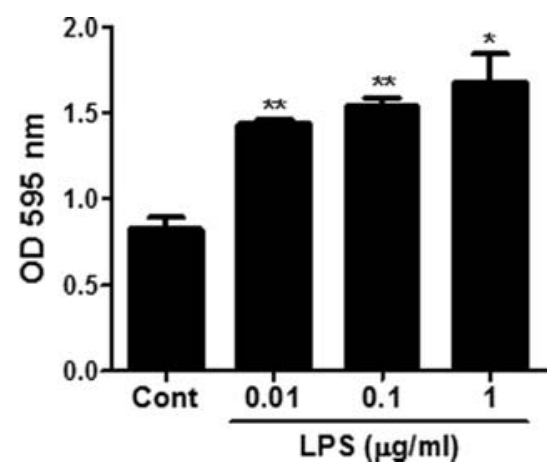

Figure 2. MDPC-23 cells were incubated in type I collagen-coated plate at the absence or presence of LPS. The cells adherent to type I collagen were stained with toluidine blue and solubilized with the addition of $100 \mu 1$ of $1 \%$ SDS. The optical density was measured at $595 \mathrm{~nm}$. Results are expressed as the means $\pm \mathrm{SD} ;{ }^{*} \mathrm{P}<0.05,{ }^{* *} \mathrm{P}<0.01$.

phospho-focal adhesion kinase (FAK), phospho-AKT, and actin antibodies (Santa Cruz Biotechnology, Santa Cruz, CA, USA) at $4^{\circ} \mathrm{C}$ overnight. The membranes were then washed three times with TBS supplemented with $0.05 \%$ Tween-20 (T-TBS), followed by incubation with secondary antibody at room temperature for $1 \mathrm{~h}$. Finally, the membranes were visualized with West-Zol ${ }^{\circledR}$ (plus) (iNtRON Biotechnology Inc., Seongnam, Korea) detection reagent using the LAS-1000 Image Reader of the Luminescent Image Analyzer (FujiFilm LifeScience, Tokyo, Japan).

Statistical analysis. Statistical significance between the groups was determined by a two-tailed Student's t-test (Excel, Microsoft). Differences were considered significant when p-values were $<0.05$.

\section{Results}

Functional expression of TLR4 in MDPC-23 cells. The gene expression of TLR4 in MDPC-23 cells was examined by RT-PCR. mRNA from mouse spleen tissue was used as positive control. The TLR4 gene was expressed in MDPC-23 cells, although its expression level was less than that in spleen (Fig. 1A). In addition, LPS led to phosphorylation of IкB- $\alpha$ after $30 \mathrm{~min}$ of stimulation (Fig. 1B), although IкB- $\alpha$ degradation was not detected. These findings suggest that TLR4 is functionally expressed in MDPC-23 cells. 

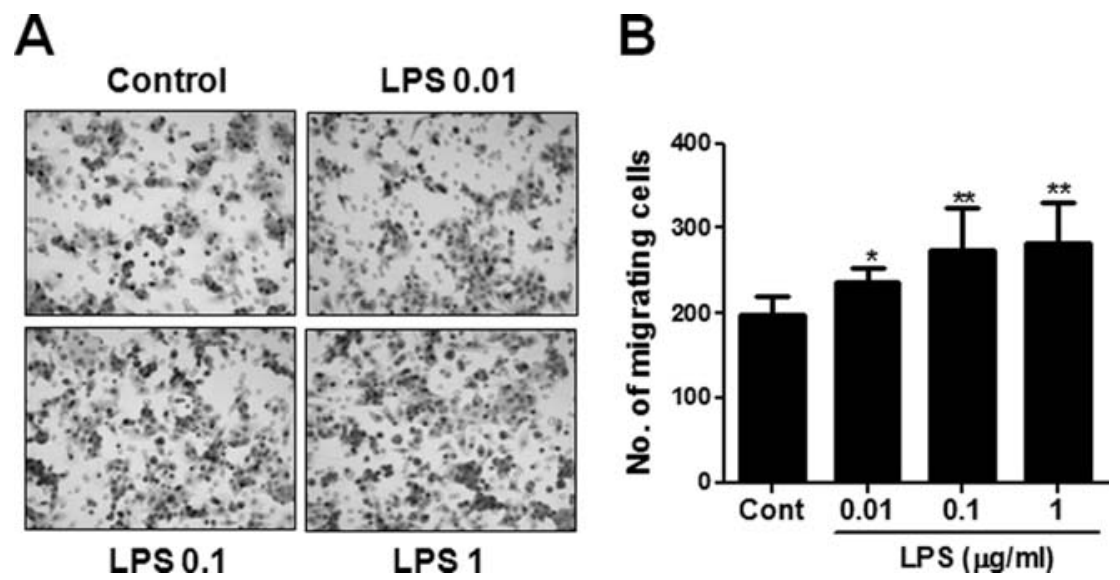

Figure 3. The migration assay was performed as described in Materials and methods. Migrating cells were fixed with methanol and stained with hematoxylin (A). The number of migrating cells was counted from five randomly selected areas (x200 magnification) (B). Results are expressed as the means $\pm \mathrm{SD}$; ${ }^{*} \mathrm{P}<0.05$, ${ }^{* *} \mathrm{P}<0.01$.

A

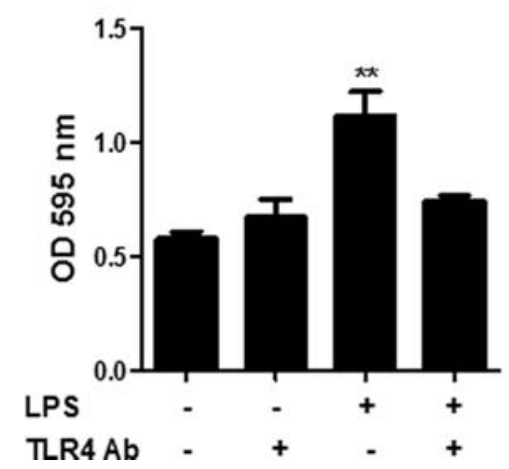

B

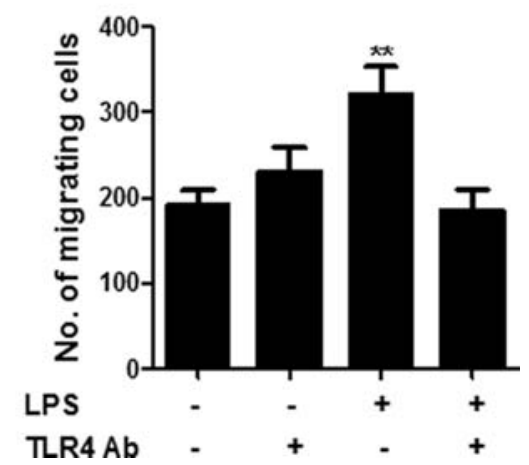

Figure 4. MDPC-23 cells were pretreated with TLR4 antibody $(10 \mu \mathrm{g} / \mathrm{ml}) 2 \mathrm{~h}$ before LPS treatment. Subsequently, adhesion (A) and migration (B) assays were performed as described in Materials and methods. Results are expressed as the means $\pm \mathrm{SD} ;{ }^{* *} \mathrm{P}<0.01$.

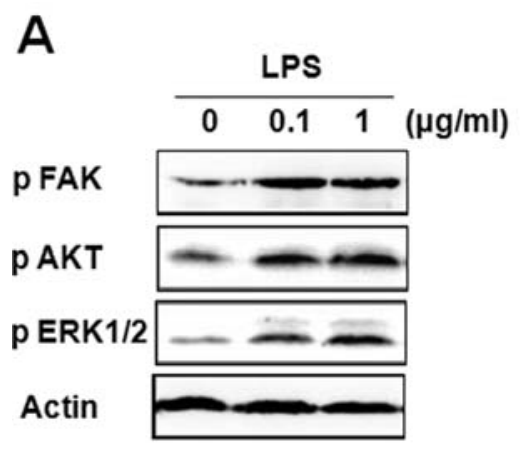

B

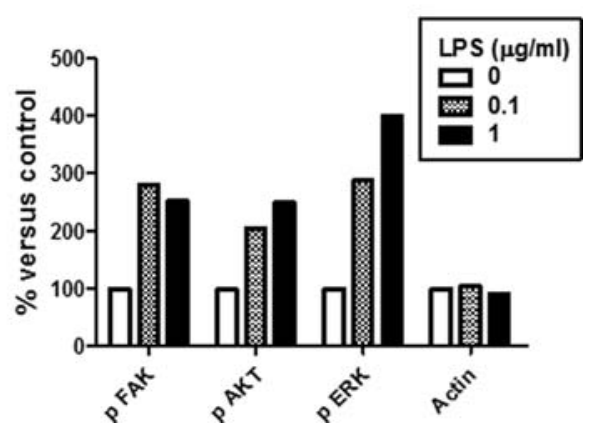

Figure 5. MDPC-23 cells were treated with LPS at indicated doses for $24 \mathrm{~h}$ and the cellular proteins were used for Western blot analysis to detect phosphorylation of FAK, AKT and ERK (A). The band densities were measured and the percentage of the value vs. control was calculated (B).

Adhesion and migration ability of MDPC-23 cells enhanced by LPS. It was examined whether LPS affects the adhesion ability of MDPC-23 cells using type I collagen-coated plate. As shown in Fig. 2, LPS stimulation significantly enhanced the adhesion ability of MDPC-23 cells on type I collagen in a dose-dependent manner. Moreover, LPS stimulation led to significant dose-dependent increase in the number of cells that migrated to the lower surface of the membrane (Fig. 3).

Involvement of TLR4 in adhesion and migration of MDPC-23 cells is enhanced by LPS. Because TLR4 is required for the LPS-induced immune response, we examined whether TLR4 
mediates the adhesion and migration of MDPC-23 cells enhanced by LPS. When TLR4 was blocked by its antibody, LPS did not promote the adhesion ability of MDPC-23 cells (Fig. 4A). Similarly, blocking of TLR4 restored the migrating ability of MDPC-23 cells enhanced by LPS (Fig. 4B). These findings indicate that LPS can promote adhesion and migration of MDPC-23 cells through a TLR4-dependent pathway.

Enhanced activation of FAK, AKT, and ERK by LPS in $M D P C-23$ cells. There are various mechanisms involved in cell migration. FAK is found to promote cell migration and invasion through the ERK and PI3/AKT signaling pathways (10). Therefore, we examined whether LPS induces the activation of these factors in MDPC-23 cells. At $24 \mathrm{~h}$ after stimulation, LPS induced the phosphorylation of FAK, AKT, and ERK in MDPC-23 cells (Fig. 5).

\section{Discussion}

TLR activation in wound healing appears to be triggered by two classes of ligands including microbial products and endogenous ligands (5). In organs such as the intestine and the skin, tissue damage results in destruction of the protective barrier and subsequent TLR activation by bacterial products, such as LPS and lipoprotein. In addition, in many organs such as the liver, kidney and the heart, tissue injury leads to the release of endogenous ligands such as heat shock proteins, high mobility group box 1 (HMGB1) and uric acid from dying and dead cells, which results in TLR activation and sterile inflammation.

The effect of TLRs on tissue injury seems to be a doubleedged sword. In ischemia-reperfusion and alcoholic liver injury, TLR 2 or TLR4 are involved in the exacerbation of epithelial injury $(11,12)$. On the other hand, in the intestine, TLR2/TLR4-MyD88 signaling is required for the epithelial regeneration following DSS-induced injury $(13,14)$. In addition, LPS signaling enhances hepatic fibrogenesis by modulating TGF- $\beta$ signaling through a TLR4/MyD88dependent pathway (15). These findings suggest that TLR signaling may be closely involved in tissue repair with distinct mechanisms.

Regeneration of a functional and living tooth is considered the most promising therapeutic strategy for the replacement of a damaged tooth (16-18). Odontoblasts that are a part of the outer surface of the dental pulp play a role in tooth repair and the regeneration process as well as in the inflammatory response. Although TLR signaling was shown to be involved in the immune response in odontoblasts (3), it remains to be clarified how TLR signaling mediates tissue repair processes of odontoblasts and/or dental pulp cells. Wound healing processes are divided into three distinct phases: first is the inflammatory and fibrogenic phase, second is the regenerative phase, and third is a remodeling phase (19). Among those phases, cell adhesion and migration are essential processes in tissue regeneration. Therefore, in this study, we examined the effect of TLR4 activation on cell migration and adhesion of MDPC-23 cells.

In human odontoblasts, the genes of TLR1-6 and 9 were functionally expressed (3). LTA led to an increase in TLR2 mRNA and protein expression and to the induction of the nuclear translocation of NF-кB. In this study, we used a murine dental papilla-derived odontoblast-like cell line, MDPC-23. The TLR4 gene was detectable and LPS treatment led to phosphorylation of I $\mathrm{B}-\alpha$, suggesting that TLR4 is functional in MDPC-23 cells. In adhesion and migration assay, LPS stimulation enhanced the adhesion and migration ability of MDPC-23 cells, which was restored by TLR4 blocking. These finding suggest that TLR4 may play a pivotal role in the tissue repair process of odontoblasts and/or dental pulp cells.

A previous study showed that LPS enhanced tumor cell adhesion and invasion through $B 1$-integrin-dependent mechanism (20). FAK has been shown to regulate integrinmediated signaling $(21,22)$. After ligand stimulation or integrin engagement, FAK becomes phosphorylated, which leads to the phosphorylation of downstream regulators such as AKT and ERK. In the present study, even though $\beta 1$ integrin expression wan not determined, LPS stimulation led to phosphorylation of FAK, AKT, and ERK in MDPC-23 cells. The precise mechanism remains to be elucidated.

In conclusion, in the present study we have shown that LPS enhanced the cell adhesion and migration of MDPC-23 cells, a process that requires TLR4, suggesting that TLR4 may play a pivotal role for tooth repair and regeneration. Because odontoblasts are found to express various TLRs and TLR signaling displayed a double-edged effect on tissue injury, it is recommended that whether and how other types of TLRs mediate tissue repair processes of odontoblasts and/or dental pulp cells should be further evaluated.

\section{Acknowledgements}

This study was supported by the MRC program of KOSEF/ MOST (R13-2008-010-01001-0).

\section{References}

1. Akira S, Uematsu S and Takeuchi O: Pathogen recognition and innate immunity. Cell 124: 783-801, 2006.

2. Lee MS and Kim YJ: Signaling pathways downstream of patternrecognition receptors and their cross talk. Annu Rev Biochem 76: 447-80, 2007.

3. Durand SH, Flacher V, Roméas A, Carrouel F, Colomb E, Vincent C, Magloire H, Couble ML, Bleicher F, Staquet MJ, Lebecque S and Farges JC: Lipoteichoic acid increases TLR and functional chemokine expression while reducing dentin formation in in vitro differentiated human odontoblasts. J Immunol 176: 2880-2887, 2006.

4. Veerayutthwilai O, Byers MR, Pham TT, Darveau RP and Dale BA: Differential regulation of immune responses by odontoblasts. Oral Microbiol Immunol 22: 5-13, 2007.

5. Kluwe J, Mencin A and Schwabe RF: Toll-like receptors, wound healing, and carcinogenesis. J Mol Med 87: 125-138, 2009.

6. Rakoff-Nahoum S and Medzhitov R: Role of toll-like receptors in tissue repair and tumorigenesis. Biochemistry (Mosc) 73: 555-561, 2008.

7. Goligorsky MS: Immune system in renal injury and repair: burning the candle from both ends? Pharmacol Res 58: 122-128, 2008.

8. Hanks CT, Sun ZL, Fang DN, Edwards CA, Wataha JC, Ritchie HH and Butler WT: Cloned 3T6 cell line from CD-1 mouse fetal molar dental papillae. Connect Tissue Res 37: 233-249, 1998.

9. Sun ZL, Fang DN, Wu XY, Ritchie HH, Bègue-Kirn C, Wataha JC, Hanks CT and Butler WT: Expression of dentin sialoprotein (DSP) and other molecular determinants by a new cell line from dental papillae, MDPC-23. Connect Tissue Res 37: 251-261, 1998. 
10. Meng XN, Jin Y, Yu Y, Bai J, Liu GY, Zhu J, Zhao YZ, Wang Z, Chen F, Lee KY and Fu SB: Characterisation of fibronectinmediated FAK signalling pathways in lung cancer cell migration and invasion. Br J Cancer 101: 327-334, 2009.

11. Wu H, Chen G, Wyburn KR, Yin J, Bertolino P, Eris JM, Alexander SI, Sharland AF and Chadban SJ: TLR4 activation mediates kidney ischemia/reperfusion injury. J Clin Invest 117: 2847-2859, 2007.

12. Uesugi T, Froh M, Arteel GE, Bradford BU and Thurman RG: Toll-like receptor 4 is involved in the mechanism of early alcohol-induced liver injury in mice. Hepatology 34: 101-108, 2001.

13. Fukata M, Chen A, Klepper A, Krishnareddy S, Vamadevan AS Thomas LS, Xu R, Inoue H, Arditi M, Dannenberg AJ and Abreu MT: Cox-2 is regulated by Toll-like receptor-4 (TLR4) signaling: role in proliferation and apoptosis in the intestine. Gastroenterology 131: 862-877, 2006.

14. Pull SL, Doherty JM, Mills JC, Gordon JI and Stappenbeck TS: Activated macrophages are an adaptive element of the colonic epithelial progenitor niche necessary for regenerative responses to injury. Proc Natl Acad Sci USA 102: 99-104, 2005.

15. Seki E, De Minicis S, Osterreicher CH, Kluwe J, Osawa Y, Brenner DA and Schwabe RF: TLR4 enhances TGF-beta signaling and hepatic fibrosis. Nat Med 13: 1324-1332, 2007.
16. Chai Y and Slavkin HC: Prospects for tooth regeneration in the 21st century: a perspective. Microsc Res Tech 60: 469-479, 2003.

17. Thesleff I: Developmental biology and building a tooth Quintessence Int 34: 613-620, 2003.

18. Yen AH and Sharpe PT: Regeneration of teeth using stem cellbased tissue engineering. Expert Opin Biol Ther 6: 9-16, 2006.

19. Gurtner GC, Werner S, Barrandon Y and Longaker MT: Wound repair and regeneration. Nature 453: 314-321, 2008

20. Wang JH, Manning BJ, Wu QD, Blankson S, Bouchier-Hayes D and Redmond HP: Endotoxin/lipopolysaccharide activates NFkappa B and enhances tumor cell adhesion and invasion through a beta 1 integrin-dependent mechanism. J Immunol 170: 795-804, 2003.

21. Miranti CK and Brugge JS: Sensing the environment: a historical perspective on integrin signal transduction. Nat Cell Biol 4: E83-E90, 2002.

22. Hynes RO: Integrins: bidirectional, allosteric signaling machines. Cell 110: 673-687, 2002 